\title{
STUDI KELAYAKAN LAPIS PERKERASAN BATU ANDESIT PADA JL. BRAGA SEBAGAI JALUR LALU LINTAS
}

\author{
Retno Utami \\ Staf pengajar Jurusan Teknik Sipil Politeknik Negeri Bandung Jl. Gegerkalong Hilir Ds.Ciwaruga \\ Bandung 40012 \\ Email: retnoutami@polban.ac.id
}

\begin{abstract}
ABSTRAK
Tujuan awal diubahnya lapis perkerasan menjadi batu andesit pada Jl. Braga adalah perubahan fungsi Jl. Braga sebagai sarana pedestrian saja. Namun, hingga saat ini, ruas Jl. Braga masih merupakan jalur lalu lintas. Perbedaan tujuan awal dengan kondisi saat ini merupakan salah satu penyebab terjadinya kerusakan berkepanjangan di ruas Jl. Braga. Proses analisa mengenai kondisi perkerasan pada ruas Jl. Braga digunakan metode failure risk model. Hasil yang didapat akan menentukan apakah desain konstruksi perkerasan yang digunakan berisiko tinggi atau tidak dengan mempertimbangkan jenis konstruksi dan peruntukannya. Hasil analisa didapat nilai risk index adalah 97,02\%. Solusi yang dapat dilakukan adalah jika kondisi Jl. Braga menjadi sarana pedestrian saja, dapat dilakukan penggantian material bed dan jointing serta proses perawatan perkerasan (pavement maintenance) dengan frekuensi yang lebih sering. Sedangkan, jika kondisi Jl. Braga sebagai jalur lalu lintas dapat dilakukan proses rekonstruksi agar tiap lapisan perkerasan mencapai kekuatan sesuai standar yang digunakan.
\end{abstract}

Kata Kunci: lapis perkerasan, batu, failure risk model

\section{Pendahuluan}

\section{IV.1. Latar Belakang}

Pada 2008, ruas Jalan Braga dilapisi batuan andesit sepanjang 370 meter. Menghabiskan 32.722 lempeng batu senilai Rp.1,8 miliar APBD Kota Bandung. April 2009 Braga rencananya sudah menjadi kawasan pedestrian, namun sampai April 2016 masih terus dilintasi kendaraan. Akibatnya, berkalikali jalan tersebut harus diperbaiki, diantaranya mengganti pasir yang semula digunakan untuk menempelkan batu andesit itu dengan semen agar lebih kuat menahan beban. Hampir setiap hari ruas Jl. Braga ini mengalami kemacetan karena pengguna jalan hanya bisa memacu kendaraannya dengan kecepatan di bawah $10 \mathrm{Km} / \mathrm{jam}$ untuk menghindari titik kerusakan jalan yang tersebar dari persimpangan Jl. Braga - Jl. Naripan hingga Jl. Braga - Jl. Lengkong. Menurut Tomtom (anggota komisi C DPRD Kota Bandung dari Fraksi Demokrat), jalan yang berbatu andesit tidak dilalui kendaraan seperti yang terdapat di negara Cina atau Singapura. "Minimal bukan kendaraan berat seperti truk yang melaluinya.
Oleh karena itu, perlu dilakukan rekayasa lalu lintas," ujarnya. Akan tetapi, kondisi Jalan Braga sekarang ini lebih menunjukkan kurang matangnya (tanpa adanya standar yang berlaku) perencanaan Pemkot terutama dari sisi teknis. Menurut dia, batuan andesit memang rentan hancur jika pemasangannya tidak sesuai standar. Misalnya, jika lapisan dasar jalan tidak rata, akan berdampak batu andesit cepat rusak. (PR, Mei 2010)

\section{IV.2. Tujuan Penelitian}

Tujuan dari studi kasus ini adalah untuk mengetahui layak atau tidaknya konstruksi perkerasan batu andesit Jl. Braga menjadi jalur kendaraan bermotor

\section{IV.3. Ruang Lingkup Penelitian}

Ruang lingkup yang akan dibahas pada studi kasus ini adalah nilai risk index pada perkerasan Jl. Braga dengan menggunakan Metode SCOTS. 


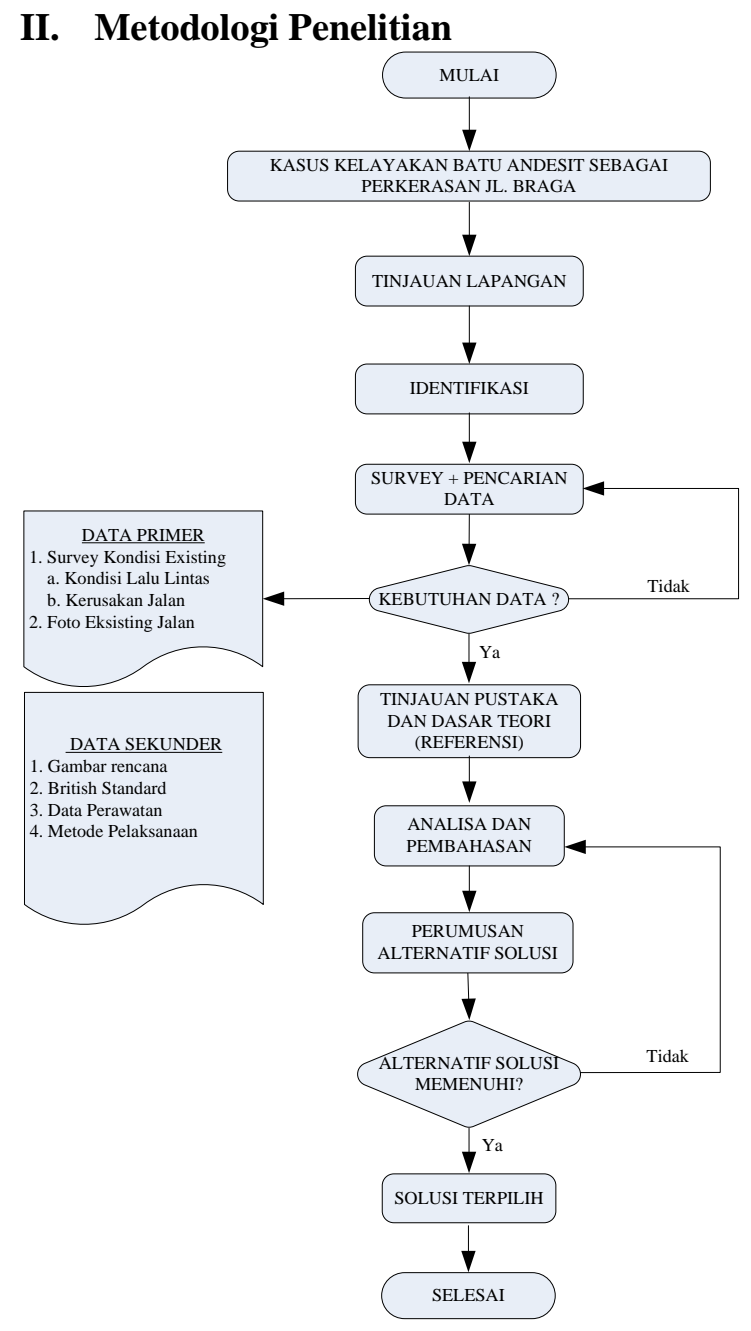

Gambar 1. Metodologi Penelitian

\section{Dasar Teori}

Jalan yang menggunakan batu sebagai permukaannya digunakan untuk meningkatkan daya tarik sebuah kota dengan memberikan kesan tradisional yang berkualitas tinggi. Selain itu, penggunaan batu juga dapat memberikan konstruksi yang tahan lama dan lebih ramah lingkungan. Dalam sebuah kajian di Eropa (McHale and Fordyce, 1999) tentang penggunaan batu alam sebagai lapis permukaan jalan menunjukkan bahwa pedoman desain yang terdapat di daerah Eropa berasal dari Jerman. Di Indonesia, belum terdapat sebuah pedoman desain mengenai batu alam sebagai lapis permukaan jalan, sehingga dalam studi kasus ini penulis menggunakan British Standard yang telah diadopsi oleh pihak Skotlandia. Meskipun pedoman desain yang ada bervariasi, namun konsep utamanya adalah :
- Batasan beban lalu lintas

- Masa layan maksimum

- Pertambahan ketebalan batu seiring pertambahan lalu lintas

- Kompatibilitas respons elastis antara lapisan atas dan bawah akibat beban

- Penggunaan pekerja yang terampil dan terlatih

Dalam penggunaan batu alam sebagai lapis permukaan jalan terdapat beberapa faktor yang menjadi perhatian utama, yaitu :

a. Lalu Lintas

Beban lalu lintas adalah faktor utama yang mempengaruhi desain lapisan permukaan dan struktur pendukung lainnya. Terdapat empat kategori beban, yaitu:

Tabel 1 Kategori pembebanan untuk Natural Stone Surfacing

\begin{tabular}{|c|l|}
\hline $\begin{array}{c}\text { Kategori } \\
\text { Pembebanan }\end{array}$ & \multicolumn{1}{|c|}{ Deskripsi } \\
\hline \hline 1 & \multicolumn{1}{|c|}{ Hanya untuk beban pedestrian } \\
\hline 2 & $\begin{array}{l}\text { Pejalan kaki dan kendaraan ringan } \\
\text { dengan maksimum beban as 2 ton } \\
\text { termasuk mobil pribadi dan } \\
\text { kendaraan ringan lainnya }\end{array}$ \\
\hline 3 & $\begin{array}{l}\text { Kendaraan dengan beban sedang } \\
\text { dengan maksimum beban as } 8 \text { ton } \\
\text { termasuk mobil servis/jasa dan bis } \\
\text { satu tingkat dengan tidak lebih dari } \\
\text { 2 as }\end{array}$ \\
\hline 4 & $\begin{array}{l}\text { Kendaraan dengan beban berat } \\
\text { dengan maksimum beban as 10 ton } \\
\text { termasuk kendaraan dengan } \\
\text { beberapa as dan kemudi ganda }\end{array}$ \\
\hline
\end{tabular}

Sumber : Natural Paving Stone Guide, SCOTS 
Tabel 2 Kategori untuk kondisi lahan untuk perkerasan berbatu

\begin{tabular}{|c|c|}
\hline $\begin{array}{c}\text { Kategori } \\
\text { Lahan }\end{array}$ & Deskripsi \\
\hline \hline A & $\begin{array}{c}\text { Dimensi jalur lalu lintas standar atau } \\
\text { dalam area terbuka } \\
\text { Kendaraan bergerak lurus sesuai } \\
\text { dengan kontur jalan }\end{array}$ \\
\hline B & $\begin{array}{c}\text { Sama seperti di atas dengan radius } \\
\text { kelengkungan }<100 \text { mm dan/atau } \\
\text { gradien }>10 \% \text {. Kendaraan berbelok. }\end{array}$ \\
\hline C & $\begin{array}{c}\text { Lebar jalur lalu lintas di bawah } \\
\text { standar }\end{array}$ \\
\hline D & $\begin{array}{c}\text { Sama seperti di atas dengan radius } \\
\text { kelengkungan }<100 \text { mm dan/atau } \\
\text { gradien }>10 \%\end{array}$ \\
\hline
\end{tabular}

Sumber : Natural Paving Stone Guide, SCOTS

b. Klasifikasi batu alam

Penggunaan batu alam ditujukan untuk mendapatkan lapis permukaan yang stabil, aman, dan tahan lama baik untuk manusia maupun untuk kendaraan yang melintas. Klasifikasi batu alam berdasarkan bentuk dapat dilihat di bawah ini :

1. Cubes memiliki ukuran yang sama untuk setiap sisinya.

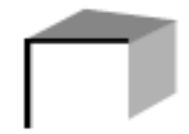

2. Setts memiliki minimum ketebalan $100 \mathrm{~mm}$ dengan panjang yang umumnya lebih besar dari ketebalannya.

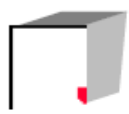

3. Blocks adalah unit yang stabil dengan ketebalan minimum $150 \mathrm{~mm}$

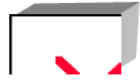

4. Tiles memiliki ketebalan maksimum $60 \mathrm{~mm}$ dan area pemasangan minimum $200 \mathrm{~mm}$

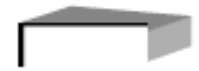

5. Flagstones memiliki ketebalan maksimum $100 \mathrm{~mm}$ dan area pemasangan minimum $300 \mathrm{~mm}$. Area pemasangan maksimum dari flagstones dibatasi dengan batas aman pengangkatan dan kekuatan lentur
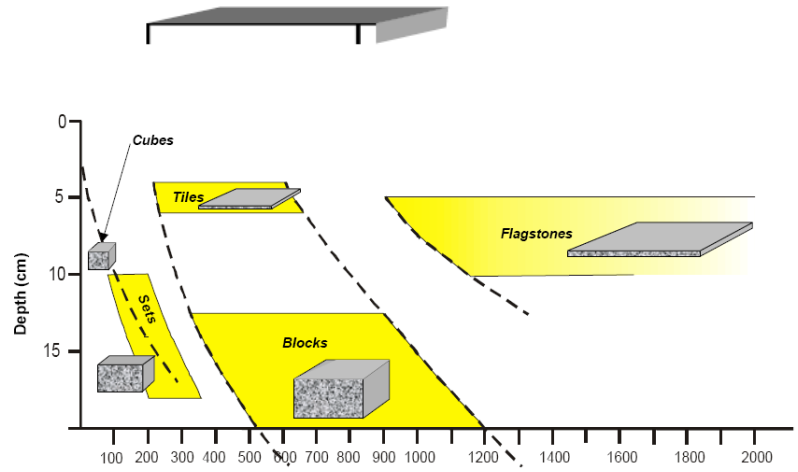

Plan area $\left(\mathrm{cm}^{2}\right)$

\section{Gambar 2 Grafik ukuran dan bentuk elemen batu}

Sumber : Natural Paving Stone Guide, SCOTS

c. Jenis lapisan permukaan

Konstruksi lapis permukaan menggunakan batu alam memiliki tiga jenis lapis pemukaan yang digunakan berdasarkan klasifikasi batu alam.

- Konstruksi lentur

Lapisan permukaan ini menggunakan unbound aggregate. Faktor-faktor yang perlu diperhatikan adalah:

> Tidak digunakan pada lalu lintas berat

> Elemen yang digunakan distabilisasi dengan mechanical interlock dan friksi

$>$ Memiliki permukaan bertekstur

$>$ Struktur pendukung sesuai dengan lapis permukaan

> Pemadatan sangat penting pada road base dan subbase untuk memastikan keseragaman daya dukung

$>$ Pendetailan pada daerah tepi sangat penting. Diperlukan rigid support di setiap tepi ke konstruksi lapis permukaan 
Pada saat pemadatan, kadar air pada bedding aggregate berada pada kadar air optimum

$>$ Penambahan ikatan pada lapis permukaan diperlukan bergantung pada kondisi lalu lintas, volume, dan lingkungan

$>$ Cubes harus diletakkan dengan pola melengkung (pola Bogan atau arc) pada daerah lalu lintas padat.

- Konstruksi kaku

> Jenis cubes, setts dan blocks kekuatan dan lebar sambungan merupakan faktor utama untuk mengontrol ketahanan struktur terhadap beban

$>$ Pada elemen yang dipotong menggunakan permukaan yang bertekstur

$>$ Struktur pendukung harus dibuat sesuai dengan lapis permukaannya

$>$ Ketebalan lapisan bedding sangat penting untuk menentukan kekakuan yang akan ditransfer pada lapisan permukaan. Pemadatan dilakukan pada kadar air optimum

$>$ Ketebalan siar harus ditentukan dan berfungsi sebagai sambungan

$>$ Terdapat selang waktu antara proses konstruksi dan waktu untuk dilewati lalu lintas

- $\quad$ Flagstones dan Tiles

$>$ Flagstones digunakan pada suatu area yang sangat luas

$>$ Flagstones yang menggunakan flexible bedding and jointing tidak memerlukan besaran pada daerah lalu lintas

> Dengan konstruksi fleksibel, pemadatan lapisan bedding sangat penting. Agregat halus harus permeable untuk menghindari lepasnya butiran dan mengurangi daya dukung

$>$ Sambungan tidak perlu diisi dengan mortar. Pasir halus dapat digunakan dengan balok beton atau urethane compound yang mengisi sambungan sekaligus memberikan ruang pergerakan
Sambungan harus dapat mengakomodasi gerakan akibat panas, minimum $2 \mathrm{~mm}$.

$>$ Flagstones dan tiles dapat digunakan dalam 2 daerah beban yang berbeda namun berada dalam satu desain

$>$ Lapisan pendukung harus dapat mengikat lapis permukaan

$>$ Kemahiran pekerja

\section{d. Proses konstruksi \\ e. Pemeliharaan \\ f. Analisa desain}

Terdapat dua pilihan analisa desain yang dipilih, yaitu metode semi-empiris dan pendekatan analisis. Metode semi-empiris didasarkan pada hasil penelitian pada perkerasan eksperimental, beberapa model matematika, dan review dari spesifikasi dan pedoman desain yang telah digunakan pada stone-paved road di Eropa. metode pendekatan analisis melibatkan analisa struktural dengan menggunakan teori-teori dasar. Sebuah model matematika digunakan untuk menentukan beban yang relevan pada desain.

\section{Metode Semi Empiris}

Metode ini terbagi menjadi 2 yaitu untuk desain baru (bagan alir A) dan rekonstruksi (bagan alir B).

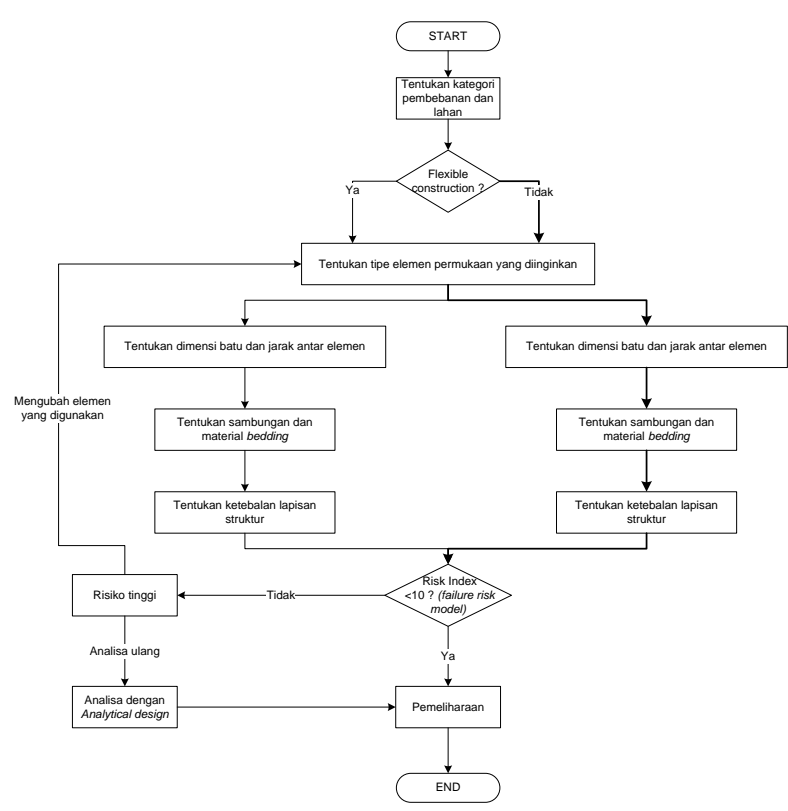




\section{Gambar 3 Bagan alir A untuk desain baru}

Sumber : Natural Paving Stone Guide, SCOTS

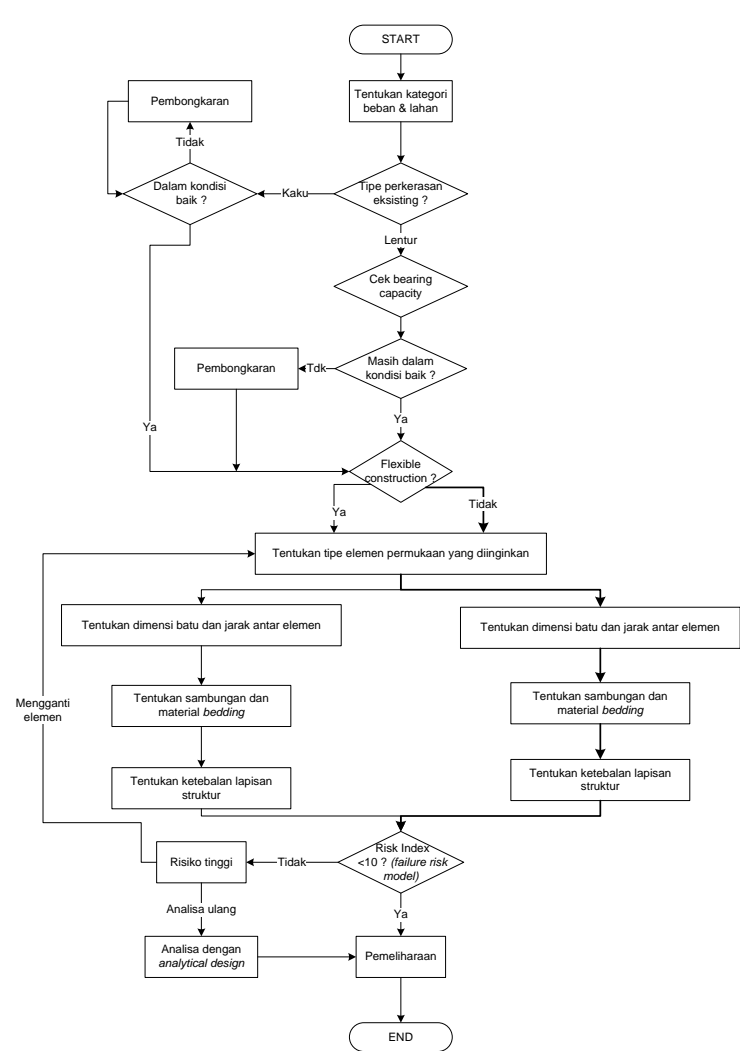

Gambar 4 Bagan alir B untuk rekonstruksi

Sumber : Natural Paving Stone Guide, SCOTS

\section{Metode Pendekatan Analisis}

Metode pendekatan analisis ini memiliki filosofi yang sama dengan struktur teknik sipil yang lain yaitu semua bagian struktur harus dapat beroperasi sesuai dengan kinerja yang seharusnya. Dasar dari metode pendekatan analisis adalah sebagai berikut :

- Menghitung beban

- Mengestimasi dimensi tiap komponen

- Mempertimbangkan material yang dipakai

- Memformulasikan model yang sesuai

- Melakukan analisis struktur dengan menggunakan teori dasar

- Membandingkan tegangan batas, ketahanan, lendutan atau deformasi yang diijinkan

- Menyesuaikan material terpilih dan/atau dimensi dari tiap komponen untuk mencapai desain yang memuaskan
- Mempertimbangkan kelayakan ekonomi dari hasil yang didapat

Failure risk model dapat bertindak sebagai metode untuk memeriksa desain perkerasan. Tujuan dari model ini adalah untuk memberikan cek pada desain berhubungan dengan kesesuaiannya dengan tujuan yang akan dicapai. Model ini juga mempertimbangkan beberapa faktor yang tidak diperhitungkan dalam proses desain seperti workmanship.

Struktur dasar dari metode ini dapat dilihat pada diagram alir berikut :

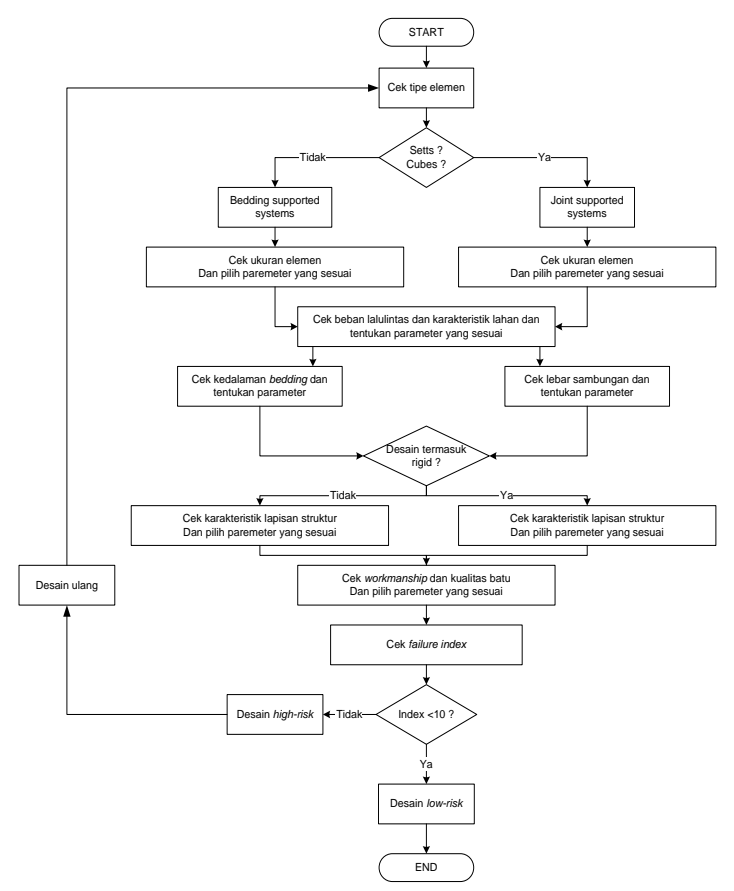

Gambar 5 Bagan alir failure risk model

Sumber : Natural Paving Stone Guide, SCOTS

Parameter yang digunakan :

a. Resistance to failure

Nilai resistance failure untuk cubes, setts dan blocks dapat dihitung dengan rumus di bawah ini :

$R_{j}=\left(A_{p} \times S_{t} \times J_{s} \times P\right)+\left(0,1 \times A_{b} \times B_{s} \times P\right)$ dimana,

$A_{p}=$ parameter untuk perimeter area

$A_{b}=$ parameter untuk luas

$\mathrm{S}_{\mathrm{t}} \quad=$ parameter untuk tekstur permukaan

$\mathrm{J}_{\mathrm{S}} \quad=$ parameter untuk kekuatan sambungan

$\mathrm{B}_{\mathrm{s}}=$ parameter untuk kekuatan bedding

$\mathrm{P} \quad=$ parameter untuk pola pemasangan

$\mathrm{R}_{\mathrm{j}} \quad=$ jointing controlled resistance 
Nilai resistance failure untuk tiles dan flagstones dapat dihitung dengan rumus di bawah ini :

$R_{b}=\left(A_{b} \times B_{s} \times P\right)+\left(0,1 \times A_{p} \times S_{t} \times J_{s}\right)$

dimana,

$\mathrm{A}_{\mathrm{p}}=$ parameter untuk perimeter area

$\mathrm{A}_{\mathrm{b}}=$ parameter untuk luas

$\mathrm{S}_{\mathrm{t}} \quad=$ parameter untuk tekstur permukaan

$\mathrm{J}_{\mathrm{S}} \quad=$ parameter untuk kekuatan sambungan

$\mathrm{B}_{\mathrm{s}}=$ parameter untuk kekuatan bedding

$\mathrm{P} \quad=$ parameter untuk pola pemasangan

$\mathrm{R}_{\mathrm{b}}=$ bedding controlled resistance

Nilai resistance failure untuk cubes, setts dan blocks dalam unbound construction dapat dihitung dengan rumus di bawah ini :

$R_{j u}=\left(0,4 \times A_{p} \times S_{t} \times J_{s} \times P\right)+\left(0,6 \times A_{b} \times B_{s} \times P\right)$ ...(iii)

dimana,

$\mathrm{A}_{\mathrm{p}}=$ parameter untuk perimeter area

$\mathrm{A}_{\mathrm{b}}=$ parameter untuk luas

$\mathrm{S}_{\mathrm{t}}=$ parameter untuk tekstur permukaan

$\mathrm{J}_{\mathrm{s}} \quad=$ parameter untuk kekuatan sambungan

$\mathrm{B}_{\mathrm{s}}=$ parameter untuk kekuatan bedding

$\mathrm{P} \quad=$ parameter untuk pola pemasangan

$\mathrm{R}_{\mathrm{ju}}=$ joint controlled resistance for unbound pavements

Tabel 4. Parameter untuk setts/cubes base area (luas) $\left(A_{b}\right)$

\begin{tabular}{|c|c|c|c|c|}
\hline $\begin{array}{c}\text { Luas } \\
\left(\mathrm{cm}^{2}\right)\end{array}$ & $\begin{array}{c}\text { Luas } \\
\text { rata-rata }\end{array}$ & $\begin{array}{c}\text { Elemen } \\
\text { pada } \\
\text { bidang } \\
\text { kontak }\end{array}$ & $\begin{array}{c}\text { Area } \\
\text { komp } \\
\text { osit }\end{array}$ & $\begin{array}{c}\text { Nilai } \\
\text { Param } \\
\text { eter }\end{array}$ \\
\hline \hline$<100$ & 80 & $4 \times 3$ & 960 & 1,3 \\
\hline $\begin{array}{c}100- \\
120\end{array}$ & 110 & $3 \times 3$ & 990 & 1,26 \\
\hline $\begin{array}{c}120- \\
240\end{array}$ & 180 & $2 \times 2$ & 720 & 1,74 \\
\hline $\begin{array}{c}240- \\
340\end{array}$ & 290 & $2 \times 2$ & 1160 & 1,08 \\
\hline$>340$ & 400 & $2 \times 2$ & 1600 & 0,78 \\
\hline
\end{tabular}

Sumber : Natural Stone Surfacing, SCOTS

Tabel 5. Parameter untuk pola pemasangan $(\mathrm{P})$

\begin{tabular}{|c|c|}
\hline Pola & Parameter \\
\hline \hline Grid & 1 \\
\hline Stretcher & 0,8 \\
\hline Bogan/segmental arch & 0,6 \\
\hline
\end{tabular}

Sumber : Natural Stone Surfacing, SCOTS
Tabel 6. Parameter untuk tekstur $\left(\mathrm{S}_{\mathrm{t}}\right)$

\begin{tabular}{|c|c|}
\hline Tekstur & Parameter \\
\hline Pemotongan & 1 \\
\hline Penggergajian & 2 \\
\hline $\begin{array}{l}\text { Penggergajian } \\
\text { dan bertekstur }\end{array}$ & 0,3 \\
\hline
\end{tabular}

Tabel 7. Parameter untuk kekuatan sambungan $\left(\mathrm{J}_{\mathrm{s}}\right)$

\begin{tabular}{|c|c|c|}
\hline $\begin{array}{c}\text { Kekuatan } \\
\text { sambungan } \\
\mathrm{N} / \mathrm{mm}^{2}\end{array}$ & Rata-rata & Parameter \\
\hline \hline$<10$ & 6 & 1 \\
\hline $10--20$ & 15 & 0,4 \\
\hline $20-30$ & 25 & 0,24 \\
\hline $30-40$ & 35 & 0,17 \\
\hline$>40$ & 50 & 0,12 \\
\hline
\end{tabular}

Sumber : Natural Stone Surfacing, SCOTS

Tabel 8. Parameter untuk kekuatan bedding $\left(\mathrm{B}_{\mathrm{s}}\right)$

\begin{tabular}{|c|c|c|}
\hline $\begin{array}{c}\text { Kekuatan bed } \\
\mathrm{N} / \mathrm{mm}^{2}\end{array}$ & Rata - rata & Parameter \\
\hline \hline$<10$ & 6 & 1 \\
\hline $10--20$ & 15 & 0,4 \\
\hline $20-30$ & 25 & 0,24 \\
\hline $30-40$ & 35 & 0,17 \\
\hline$>40$ & 50 & 0,12 \\
\hline
\end{tabular}

Sumber : Natural Stone Surfacing, SCOTS

b. Parameter untuk beban lalu lintas

Kategori pembebanan sama dengan kategori pembebanan seperti pada tabel 1. Namun, ditambahkan satu kategori lagi yaitu kategori 5 untuk konsentrasi lalu lintas berat seperti jalur umum transportasi bus atau kendaraan berat lainnya. 
c. Lebar sambungan

Tabel 9 Parameter untuk lebar sambungan $\left(J_{\mathrm{w}}\right)$

\begin{tabular}{|c|c|}
\hline $\begin{array}{c}\text { Lebar sambungan } \\
(\mathrm{mm})\end{array}$ & Parameter \\
\hline \hline$<5$ & 3 \\
\hline $5--10$ & 1,5 \\
\hline $10--15$ & 1 \\
\hline $15--20$ & 1,5 \\
\hline$>20$ & 2 \\
\hline
\end{tabular}

Sumber : Natural Stone Surfacing, SCOTS

d. Ketebalan bedding

Tabel 10 Parameter untuk tebal bedding $\left(B_{t}\right)$

\begin{tabular}{|c|c|}
\hline $\begin{array}{c}\text { Tebal bedding } \\
(\mathrm{mm})\end{array}$ & Parameter \\
\hline \hline$<20$ & 4 \\
\hline $20-30$ & 2 \\
\hline $30-50$ & 1 \\
\hline $50-70$ & 2 \\
\hline$>70$ & 4 \\
\hline \multicolumn{2}{|c|}{ Sumber : Natural Stone Surfacing, SCOTS }
\end{tabular}

e. Lapis pendukung

Tabel 11 Parameter untuk Lapisan Pendukung $\left(\mathbf{L}_{s r}\right)$

\begin{tabular}{|c|c|c|c||c|c}
\hline Sesuai & 1 & $\begin{array}{c}\text { Tidak } \\
\text { sesuai }\end{array}$ & 4 & \multicolumn{2}{||}{} \\
\hline \hline \multicolumn{2}{|c||}{ Butiran } & \multicolumn{2}{c|}{ Beraspal } & \multicolumn{2}{c}{ Ikatan semen } \\
\hline \hline Pemadatan & Parameter & $\begin{array}{c}\text { Kekakuan } \\
(\mathrm{Gpa})\end{array}$ & Parameter & $\begin{array}{c}\text { Kekuatan } \\
\left(\mathrm{N} / \mathrm{mm}^{2}\right)\end{array}$ & Parameter \\
\hline $\begin{array}{c}\text { to series } \\
800\end{array}$ & 1 & $<2$ & 2 & $<20$ & 2 \\
\hline spek. Lain & 5 & $2-3$ & 1,2 & $20-30$ & 1 \\
\hline $\begin{array}{c}\text { tidak ada } \\
\text { spek. }\end{array}$ & 15 & $3--4$ & 1 & $30-40$ & 0,9 \\
\hline & & $4--6$ & 0,9 & $>40$ & 0,8 \\
\hline & $>6$ & 0,8 & & \\
\hline
\end{tabular}

Sumber : Natural Stone Surfacing, SCOTS

\section{f. Workmanship}

Tabel 12 Parameter untuk workmanship (W)

\begin{tabular}{|c|c|}
\hline Kategori & Parameter \\
\hline \hline Jelek & 10 \\
\hline Sedang & 3 \\
\hline Bagus & 1 \\
\hline
\end{tabular}

g. Kualitas batu alam

Tabel 13 Parameter untuk kualitas batu alam (Q)

\begin{tabular}{|c|c|}
\hline Sesuai spek. & Parameter \\
\hline \hline Ya & 1 \\
\hline Tidak & 1,1 \\
\hline
\end{tabular}

h. Prosedur perhitungan

$\mathrm{FI}_{\mathrm{nsp}}=\left(\mathrm{R}_{\mathrm{j}}\right.$ atau $\mathrm{R}_{\mathrm{ju}}$ atau $\left.\mathrm{R}_{\mathrm{b}}\right) \times \mathrm{T} \times \mathrm{C}_{\mathrm{s}} \mathrm{x}$ $\left(\mathrm{J}_{\mathrm{w}}\right.$ atau $\left.\mathrm{B}_{\mathrm{t}}\right) \times \mathrm{L}_{\mathrm{sr}} \times \mathrm{W} \times \mathrm{Q}$

i. Penggunaan Failure Index (Failure Index $=$ Risk Index)

Jika nilai akhir didapat lebih dari 10, maka ada kemungkinan perkerasan tersebut akan mengalami kerusakan. Kerusakan ini diprediksi akan lebih dari sekadar kegagalan lokal dan cenderung memerlukan perbaikan menyeluruh bukan hanya pemeliharaan pada lapis permukaan saja.

\section{Analisis}

\section{IV.1. Kondisi Eksisting}

\section{Jenis Struktur Perkerasan}

Berdasarkan jenis konstruksi lapis permukaan dengan batu alam pada gambar di bawah, konstruksi yang digunakan pada $\mathrm{Jl}$. Braga dapat diklasifikasikan pada jenis konstruksi kaku Hal ini dapat dilihat dari penggunaan material bedding dan jointing yang berupa mortar. 


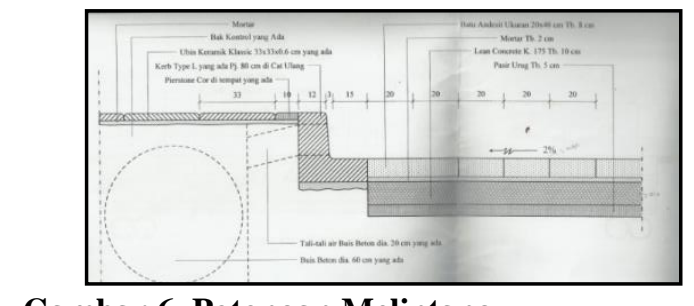

Gambar 6. Potongan Melintang

Sumber : Dinas Bina Marga Kota Bandung

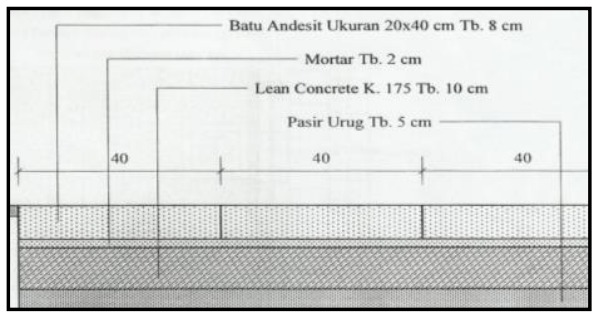

Gambar 7. Susunan Struktur Perkerasan Jl. Braga

Sumber : Dinas Bina Marga Kota Bandung

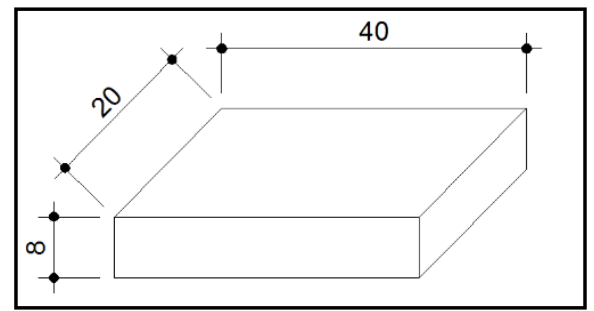

Gambar 8. Ilustrasi Elemen Batu

Sumber: Hasil survey

Seperti terlihat pada gambar, elemen menggunakan ukuran $40 \times 20 \times 8 \mathrm{~cm}$ dan memiliki luas permukaan $800 \mathrm{~cm}^{2}$.

Ruas Jl. Braga yang menggunakan andesit hampir setiap hari dipadati oleh kendaraan. Pada jam sibuk, terjadi antrean kendaraan yang disebabkan antara lain oleh on street parking dan kerusakan jalan. Onstreet parking di Jl. Braga menghabiskan hampir setengah badan jalan, sehingga Jl. Braga yang awalnya 2 lajur hanya berfungsi 1 lajur saja. Selain itu, kerusakan perkersan di berbagai titik menyebabkan kendaraan bergerak perlahan untuk menghindari titik kerusakan tersebut. kendaraan yang mendominasi lalu lintas di $\mathrm{Jl}$. Braga adalah kendaraan pribadi berjenis sepeda motor dan kendaraan ringan (mobil pribadi, pick up dan minibus). Berikut adalah presentasi komposisi kendaraan :

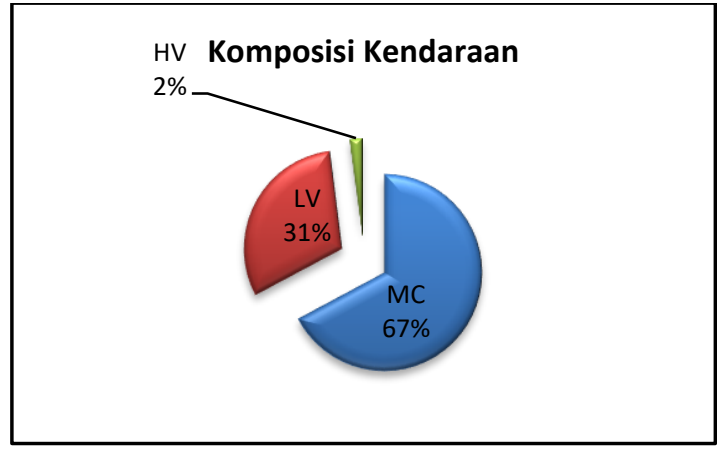

Gambar 9. Komposisi Kendaraan

Sumber : Hasil survei

Pada awalnya perubahan konstruksi menjadi batu andesit hanya diperuntukkan bagi sarana pedestrian. Namun, dalam realisasi, rencana tersebut tidak dapat dilakukan. Salah satu faktor yang menyebabkan terhambatnya realisasi tersebut adalah karena Jl. Braga merupakan satu-satunya akses menuju $\mathrm{Jl}$. Lembong dan Naripan dari arah Cikapundung.

Sehingga, desain awal Jl. Braga yang hanya diperuntukkan untuk sarana pedestrian digunakan juga untuk lalu lintas kendaraan. Maka, tidak heran konstruksi Jl. Braga sering terjadi kerusakan karena konstruksi perkerasan yang sekarang dipakai untuk lalu lintas kendaraan memang tidak di desain untuk menerima beban kendaraan seperti terlihat pada komposisi kendaraan yang melintas di Jl. Braga

Kerusakan yang banyak terjadi pada ruas $\mathrm{Jl}$. Braga adalah debonding of jointing material, broken and damaged material, missing elements, depression or bumps, dan contamination. Berikut adalah presentasi kerusakan dibandingkan dengan luas jalan yang menggunakan batu andesit pada ruas $\mathrm{Jl}$. Braga : 
Tabel 14 Rekapitulasi Presentasi Kerusakan Jl. Braga

\begin{tabular}{|c|c|c|}
\hline Kerusakan & Luas & Presentasi \\
\hline $\begin{array}{c}\text { Debonding of } \\
\text { jointing material }\end{array}$ & 3185300 & 11,29 \\
\hline $\begin{array}{c}\text { Depression and } \\
\text { bumps }\end{array}$ & 2614500 & 9,27 \\
\hline Missing elements & 13200 & 0,05 \\
\hline $\begin{array}{c}\text { Broken or } \\
\text { damaged } \\
\text { elements }\end{array}$ & 171200 & 0,61 \\
\hline Contamination & 80000 & 0,28 \\
\hline Jumlah & 6064200 & 21,49 \\
\hline
\end{tabular}

\section{IV.2. Analisa Data}

Lapisan struktur perkerasan yang tidak memenuhi persyaratan, antara lain :

Tabel 9 Perbandingan Desain dan Standard

\begin{tabular}{|c|c|c|c|}
\hline Pembanding & Desain & $\begin{array}{c}\text { Min. } \\
\text { Persyaratan }\end{array}$ & Keterangan \\
\hline \multicolumn{4}{|l|}{ Surface } \\
\hline Ketebalan & $8 \mathrm{~cm}$ & $10 \mathrm{~cm}$ & $\begin{array}{c}\text { Dalam BS, } \\
\text { ketebalan } \\
\text { termasuk ke } \\
\text { dalam setts. } \\
\text { Sehingga } \\
\text { dalam } \\
\text { proses } \\
\text { analisa } \\
\text { desain } \\
\text { digunakan } \\
\text { analisa } \\
\text { untuk setts. } \\
\text { Namun, } \\
\text { untuk } \\
\text { jangka } \\
\text { panjang } \\
\text { sebagai jalur } \\
\text { lalu lintas, } \\
\text { tebal elemen } \\
\text { harus sesuai } \\
\text { dengan } \\
\text { minimal } \\
\text { persyaratan. }\end{array}$ \\
\hline \multicolumn{4}{|l|}{ Bedding } \\
\hline Ketebalan & $2 \mathrm{~cm}$ & $\begin{array}{l}2,5 \mathrm{~cm}-4 \\
\mathrm{~cm}\end{array}$ & \\
\hline
\end{tabular}

\begin{tabular}{|c|c|c|c|}
\hline Kekuatan & $\begin{array}{l}5 \\
\mathrm{~N} / \mathrm{mm}^{2} \\
\end{array}$ & $10 \mathrm{~N} / \mathrm{mm}^{2}$ & \\
\hline Jointing & $\begin{array}{l}\text { Max. } 3 \\
\text { mm }\end{array}$ & Min. $8 \mathrm{~mm}$ & \\
\hline \multicolumn{4}{|l|}{ Base } \\
\hline Ketebalan & $10 \mathrm{~cm}$ & $15 \mathrm{~cm}$ & \\
\hline \multicolumn{4}{|l|}{ Sub Base } \\
\hline Ketebalan & $5 \mathrm{~cm}$ & $\begin{array}{l}7,5 \mathrm{~cm}-15 \\
\mathrm{~cm}\end{array}$ & \\
\hline $\begin{array}{l}\text { Metode } \\
\text { pelaksanaan }\end{array}$ & - & Tabel 5.5 & $\begin{array}{c}\text { Tidak } \\
\text { didapatnya } \\
\text { data } \\
\text { mengenai } \\
\text { metode } \\
\text { pelaksanaan } \\
\text { menghambat } \\
\text { analisa. } \\
\text { Namun, } \\
\text { melihat apa } \\
\text { yang terjadi } \\
\text { di lokasi } \\
\text { tinjauan dan } \\
\text { dari } \\
\text { berbagai } \\
\text { referensi, } \\
\text { dapat } \\
\text { dikatakan } \\
\text { metode } \\
\text { pelaksanaan } \\
\text { tidak sesuai } \\
\text { dengan } \\
\text { standar. }\end{array}$ \\
\hline
\end{tabular}

Sumber : Hasil analisa

Risk index digunakan untuk menghitung apakah desain yang digunakan memiliki risiko tinggi saat masa layan atau tidak. Jika termasuk risiko tinggi maka diperlukan untuk me-review desain, mengganti beberapa besaran yang digunakan namun jika berisiko rendah maka desain dapat digunakan selama masa layan yang ditentukan.

Hasil risk index didapat angka 97,02 > 10. Angka ini menunjukkan bahwa desain yang digunakan memiliki risiko tinggi. Arti dari risiko tinggi adalah bahwa struktur perkerasan yang didesain tidak sesuai dengan apa yang direncanakan pada awalnya. Ketidaksesuaian ini dapat terletak pada elemen batu yang digunakan, beban yang melintas, ataupun faktor-faktor lainnya yang diperhitungkan dalam failure risk index. Dalam kasus $\mathrm{Jl}$. Braga, faktor yang menyebabkan risk index > 10 adalah: 
- tebal elemen batu yang digunakan

- kekuatan ikatan

- $\quad$ kekuatan bedding

- lebar sambungan

- kekuatan lapisan pendukung

- beban yang melintas

\section{IV.3. Alternatif Solusi}

Dari tiga tinjauan di atas, disimpulkan alternatif solusi terhadap permasalahan yang ada. Solusi tersebut adalah :

1. Dikembalikan ke peruntukkan awal yaitu menjadi sarana pedestrian

2. Jika tetap difungsikan sebagai jalur lalu lintas, maka langkah yang dapat dilakukan adalah :

a. Mengganti material lapisan bed dan material sambungan

b. Membatasi jenis kendaraan yang masuk

c. Melakukan rekonstruksi dengan ketebalan tiap lapisan sesuai standar

d. Melakukan re-desain

\section{Kesimpulan dan Saran}

Berdasarkan hasil analisa, nilai risk index yang didapatkan adalah sebesar 97,02. Nilai tersebut melebihi batas normal yaitu, 10. Ada beberapa alternatif solusi yang bisa dilakukan pada Jl. Braga agar nilai risk index mendekat normal. Alternatif solusi tersebut dapat dipisahkan menjadi dua kondisi yaitu kondisi menjadi sarana pedestrian saja dan kondisi tetap dipergunakan sebagai jalur lalu lintas. Jika dilakukan kondisi menjadi sarana pedestrian saja, dapat dilakukan penggantian material bed dan jointing serta proses perawatan perkerasan (pavement maintenance) dengan frekuensi yang lebih sering. Sedangkan, jika dilakukan kondisi sebagai jalur lalu lintas dapat dilakukan proses rekonstruksi agar tiap lapisan perkerasan mencapai kekuatan sesuai standard yang digunakan.

\section{Daftar Pustaka}

BS 7533 : 1992. Guide For The Structural Design of Pavements Constructed With Clay or Concrete Block Pavers. London: British Standard Institution.

BS EN 1342 : 2001. Setts of natural stone for external paving. Requirements and test methods. London: British Standard Institution.

Matheson, G.D. 1999. The Characterisation and Specification of Natural Stone Setts for Streetscape Work. Matlock Consulting Ltd.

SCOTS. 2004. Natural Paving Stone Surfacing - Good Practice Guide. Skotlandia. 